\title{
Забытый герой. Жизнь и научное наследие Саркиса Вараковича Саркисяна (1899-1981 гг.)
}

\author{
О монографии C.B. Саркисяна, или Non Numeranda, Sed Ponderanda Argumenta \\ («Доказательства хороши качеством, а не количеством»)
}

\author{
Арутюнян А.Ж. ${ }^{1}$, Казаров С.С. ${ }^{2}$ \\ 1) Ереванский государственный университет, \\ Армения, 0025, Ереван, ул. Х. Абовяна, 52; \\ e-mail: hakobharutyunyan@ysu.am \\ Южный Федеральный университет; \\ 344006, Россия, г. Ростов-на-Дону, ул. Большая Садовая, 105 \\ e-mail: ser-kazarov@yandex.ru
}

\begin{abstract}
Аннотация. Необычный жизненный путь прошел видный историк и военно-политический деятель Саркис Варакович Саркисян. Он был участником двух мировых войн, а после Великой Отечественной войны преподавал в Ереванском медицинском институте, передавая свой богатый опыт молодым, особенно военным врачам. Параллельно занимался изучением военной истории древней и раннесредневековой Арменни (со второй половины III тыс. до н. э. вплоть до первых арабских нашествий на Армению (начало VII в.). В армянской исторической науке это была первая успешная попытка создания обобщенной работы по истории военного искусства Армении.
\end{abstract}

Ключевые слова: Саркис Варакович Саркисян, Армения (древняя, раннесредневековая), военное искусство, войско, расстановка сил, атака, отступление.

Для цитирования: Арутюнян А.Ж., Казаров С.С. 2021. Забытый герой. Жизнь и научное наследие Саркиса Вараковича Саркисяна (1899-1981 гг.). Via in tempore. История Политология. 48 (4): 820-826. DOI: 10.52575/2687-0967-2021-48-4-820-826.

\section{Forgotten hero. Life and scientific heritage of Sarkis Varakovich Sarkisyan (1899-1981)}

\author{
Hakob Zh. Harutyunyan, Sarkis S. Kazarov \\ Yerevan State University, \\ 52 Kh. Abovyan St., Yerevan 0025, Armenia \\ E-mail: hakobharutyunyan@ysu.am; \\ Southern Federal University, \\ 105 Bolschaya Sadovaya, Rostov-on-Don 344006, Russia \\ E-mail: ser-kazarov@yandex.ru
}

\begin{abstract}
Sargsyan Sargis Varakovich (Varagovich) (5.09.1899 - 26.10.1981) - Armenian militarypolitical leader, retired colonel. Unusual life path was Sargis Varakovich. He was a participant in two world wars, after the Second World War he taught at the Yerevan Medical Institute, passing on his rich experience to young, especially to military doctors. In parallel he studied the military history of ancient and early medieval Armenia (from the second half of the III Millennium BC until the first Arab invasions of Armenia (beginning of the VII century). S.V. Sargsyan was the first in Armenian historiography to study ancient and early medieval Armenian military affairs. The result of these studies was the publication in 1969 of the monograph «From the History of Armenian Military Art». In Armenian historiography this was the first attempt to create a generalized work on the history of military art in Armenia. During the last decade,
\end{abstract}


Armenian historiography has made a big step in the study of ancient Armenian military art. However, all research in this area is of a historical and archaeological character, and so far the work of S.V. Sargsyan remains the only purely military-theoretical work in Armenian historiography.

Key words: Sarkis Varakovich Sarkisyan, Armenia (ancient, early medieval), military art, army, balance of power, attack, retreat.

For citation: Harutyunyan Hakob Zh., Kazarov S.S. 2021. Forgotten hero. Life and scientific heritage of Sarkis Varakovich Sarkisyan (1899-1981). Via in tempore. History and political science. 48 (4): 820-826 (in Russian). DOI: 10.52575/2687-0967-2021-48-4-820-826.

\section{Введение}

Саркисян Саркис Варакович (Варагович) (5.09.1899 - 26.10.1981) - армянский военно-политический деятель, полковник в отставке. Будучи 15-летним мальчиком, участвовал в военных действиях Первой мировой войны. Участвовал в Сардарапатском и Баш Апранском сражениях против турецких захватчиков в 1918 г. Принимал участие в военных действиях Второй мировой войны.

С.В. Саркисян первым в армянской историографии стал изучать древнее и раннесредневековое армянское военное дело. Итогом этих исследований стало издание в 1969 г. монографии «Из истории армянского военного искусства».

\section{Результаты и их обсуждение}

Монография С.В. Саркисяна посвящена изучению истории армянского военного искусства с незапамятных времен почти до середины VII в. н. э. Данный труд можно разделить на несколько частей: формирование военного искусства в Армении с древнейших времен до династии Оронтидов (до I пол. VII в. до н. э.); военное искусство эпохи царей династии Оронтидов (I пол. VII в. до н. э. - 201 г. до н. э.), военное искусство эпохи царей династии Арташесидов (189 г. до н. э. - 1 г. н. э.; военное искусство эпохи царей Аршакидов (52/66 - 428 гг.); военное искусство в постгосударственную эпоху: военное искусство Армении эпохи раннего феодализма; военное искуство в годы первых арабских нашествий в Армению (почти до середины VII в.).

Исходной точкой изучения поставленных проблем является беглый обзор Армянского нагорья для определения естественных препятствий, которые во все времена мешали врагам Армении во время нашествий ${ }^{113}$. В монографии представлена организация армии в Армении, после чего автор переходит к изучению вопросов вооружения и экипировки войск: дано краткое описание вооружения солдат со времен использования стрел до распространия боевых машин. Здесь есть упоминание и о военной машине онагр (onagres). Это подсказывает, что в Армении, как и в других странах, до распространения конницы в армии использовали осла (equus hemionus onager) ${ }^{114}$.

Изложение начинается с первого сражения в истории армянского народа, о котором упоминает Мовсес Хоренаци (V в.), между праотцом армян Айком и тираном Вавилонии Белом. Далее автор переходит к описанию войск Оронтидской Армении при царе Ерванде I (580-560 гг. до н. э.). О этих событиях свидетельствует и Ксенофонт. Военное дело в Армянском царстве стало успешно развиваться под натиском агрессии соседних держав. Армения тогда имела сорокатысячную пехоту и восьмитысячную конницу (Xen. Cyr., II, I, 6; Strabo. XI, 14, 15) ${ }^{115}$.

113 [Саркисян, 1969, с. 10-11]. Одним из лучших описаний Армянского нагорья считается работа Х.Ф.Б. Линча [Линч, 1910].

114 [Нефедкин, 2003, с. 212-216]. Данному вопросу посвящена работа средневекового неизвестного армянского автора XIII в. [Лечебник лошадей и вообще вьючных животных, 1980].

${ }^{115}$ См. также: [Арутюнян, 2012b, c. 150-174]. 
После распада Ахеменидов весь Ближний Восток вступил в эпоху эллинизма. Однако Армения при Оронтидах отстранила себя от процесса эллинизации, что стало причиной отставания Армянского царства от соседних государств. В новую эру своего развития Армения вступила после прихода к власти династии Арташесидов, основателем которой стал Арташес I (189-160 гг. до н. э.).

После издания монографии С.В. Саркисяна в аспекте изучения эллинистических армий написано много работ, особенно о катойкизации. Впервые об этом в армянской историографии поверхностно сообщил акад. Г.Х. Саркисян, хотя косвенные намеки есть и у С.В. Саркисяна ${ }^{116}$. Основываясь на скудных сведениях об Арташесе как военачальнике, С.В. Саркисян заключает, что он мог предугадать тактику противника на основе расстановки войск перед сражениями.

С.В. Саркисян особое внимание уделяет изучению вопроса военной тактики Тиграна II Великого. При изучении сражения у р. Арацани 68 г. до н. э. исследователь опирается на сведения историка Диона Кассия, который выясняет причины поражения Лукулла, а далее - причины бегства римлян из Армении (Dio. XXXVI, III, 3; Sallust. IV, 69) ${ }^{117}$. Исследователем составлены схематические карты сражений и представлена расстановка войск перед началом Тигранакертского сражения. Далее достаточно подробно проанализированы походы Помпея, Красса и Антония в Армению ${ }^{118}$.

В последующих трех главах книги (гл. VI-VIII) автор исследует военное искусство царей династии армянских Аршакидов (52/66 - 428 гг., на арм. Аршакуни). Особое внимание уделено сражению возле Кастеллум Воландум (Tacit. Ann. XIII, 41.) ${ }^{119}$, при этом оговорено участие мардов в военных действиях ${ }^{120}$.

Автор показал, как могут вести согласованные действия две разные армии: начать действия одновременно и как минимум в двух направлениях; обойти противника с флангов в неожиданных для него местах и взять его «в щипцы»; сделать все, чтобы расколоть силы противника и уничтожить его по частям; вести партизанскую войну не в одном направлении, как прежде, а сразу в нескольких ${ }^{121}$. Выводы сделаны на основании работ Тацита (Tacit. Ann. XIII, 35, 39, 41, XIV, 26, XV, 3, 6, XV, 6 и слл.) ${ }^{122}$.

Ситуация коренным образом изменилась после прихода к власти в Римской империи второго императора новооснованной династии Антонинов (96-192 гг.) Траяна. Военные действия между тремя государствами (Римом, Парфией и Арменией) возобновились, когда в империи стал править Марк Аврелий. Поводом для новой войны против Армении и Парфии послужило назначение парфянами Пакора царем Аршакидской Армении. Генеральное сражение между воюющими сторонами произошло при Элегии ${ }^{123}$. Это сражение первым среди исследователей С.В. Саркисян рассматривает подробно не только в дислокационном ракурсе, но и с военно-стратегической точки зрения. Автор находит, что успех

116 См. [ИАН, 1971, с. 534, 595, 674, 687; Саркисян, 1969, с. 58]. Схему Ервандашатского сражения, составленную С.В. Саркисяном, см. http://armenianhouse.org/sargsyan/razmarvest/9.html (на арм. яз.); также [Кащеев, 1993].

117 С.В. Саркисян один из первых обратил особое внимание на сведения Саллюстия, которые весьма объективны [Саркисян, 1969, с. 95, 97-98; Арутюнян, 2014a, с. 81-86]. Карту расположения сил при сражении у p. Арацани, составленную С.В. Саркисяном, см.: http://armenianhouse.org/sargsyan/razmarvest/9.html.

118 Карту военных действий между Тиграном и Лукуллом 67 г. до н. э., составленную С.В. Саркисяном, см.: http://armenianhouse.org/sargsyan/razmarvest/9.html. [Разин, 1999, с. 402 и слл.].

119 См. [Саркисян, 1969, с. 123-124]. Нами выяснено, что Кастеллум Воландум - это оз. Гайлату, которое в настоящее время находится в Турции. См. [Арутюнян, 2010, с. 154-159; Poirot, 2003, с. 89-91].

${ }^{120}$ Более подробно см. [Арутюнян, 2014b, c. 74-81; Арутюнян, 2012b, c. 47-54].

${ }^{121}$ См. [Саркисян, 1969, с. 136-137].

${ }^{122}$ См. также [Саркисян, 1969, с. 136-137; ИАН, 1971, с. 734, 768-776 и слл.; Фаррох, 2009, с. 161-164].

123 См.: http://armenianhouse.org/sargsyan/razmarvest/7.html; также [ИАН, 1971, с. 782 и слл. (авт. Еремян С.Т.); Манандян, 1978]. 
союзников против римлян был обусловлен не только правильным выбором местности, но и искусством распределения войск ${ }^{124}$.

С.В. Саркисян одним из первых проанализировал армянский первоисточник «Зоранамак» (Войсковое письмо, Войсковая бумага; на англ. Register list; первоисточник был обнаружен Н.Г. Адонцем). Однако он рассмотрел этот документ с точки зрения военного. Исследователь находит, что в конце IV в. армянское нахарарское войско состояло из 86 тысяч (из них 49-50 тысяч служили в коннице), а в армии Аршакидов служило 36 тысяч человек. Автор точно опредляет численность войск четырёх питиашхов ${ }^{125}$.

В заключительной 10-й главе С.В. Саркисян рассматривает армянское военное искусство в VI - нач. VII вв. Особое внимание автор уделяет военному искусству Вардана Мамиконяна Младшего (Вардан Красный), который руководил народно-освободительным движением против персов в Восточной Армении в 571-572 гг. Его полководческое искусство блестяще было проявлено как в сражении 571 г. под Двином, так и на поле Хагамаха. Несмотря на то, что персы имели двадцатитысячное войско и хорошо обученных боевых слонов, Вардан искусно использовал местность для окончательной победы. Он обошел противника с двух сторон, чем привлек его внимание и тем самым заставил вражеские арьергардные резервные силы вступить в бой раньше времени. Так он смог окружить неприятеля и разбить его. С.В. Саркисян заключает: «Своей тактикой ведения боя Вардан Младший превзошел своих предшественников» (Procop. Bell.) ${ }^{126}$.

В заключении автор останавливается на изучении военного искусства Ваана Мамиконяна или Гайла (волк) Ваана. Своим прозвищем полководец обязан тому, что, подобно волку, организовывал внезапные нападения на врага.

Все упомянутые военные события были хорошо изучены многими специалистамиисториками. С.В. Саркисян эти же вопросы рассматривает совершенно в другом ракурсе. Как военный, прошедший три войны, он смотрит на происходящие события через призму мировоззрения военного специалиста, что существенно отличает его исследование от других. Никто до него и после него не рассматривал эти вопросы в высшеупомянутом ракурсе.

Почему мы назвали нашу рецензию «Доказательства хороши качеством, а не количеством»? Кроме сражений, о которых пишет и анализирует С.В. Саркисян, в истории армянского народа происходило еще много боев, больших и малых. Однако автор, анализируя важнейшие из них, развивает мысль о прогрессе военного искусства в Армении с незапамятных времен вплоть до арабских нашествий. Прочитав эту книгу, можно сделать вывод, что автор хорошо понимал военное искусство, тактику ведения боя. Между строк древних историков он смог прочитать нечто новое, иное, чего не смогли сделать историки, филологи, лингвисты и другие специалисты гуманитарного профиля.

\section{Выводы}

Смело можно заявить, что эта книга по качеству содержания превосходит работы Ханса (Ганс) Готлиба Леопольда Дельбрюка (Hans Gottlieb Leopold Delbrück - 1848-1929 гг.) и Ф. Меринга (1846-1919 гг.) и находится на том же уровне, что и работа Е.А. Разина $\left(1898-1964\right.$ гг.) ${ }^{127}$.

124 [Саркисян, 1969, с. 144-145]. Также [Манандян, 1978, с. 45-50; Фаррох, 2009, с. 179-181]. Е.А. Разин достаточно подробно изучает тактику ведения войны как у римлян, так и парфян. См.: [Разин, 1999, с. 406-445 (тактика римлян), 236 и слл., 397 и слл. (тактика парфян); Poirot, 2003, с. 154 и слл.].

${ }_{125}$ См. [Адонц, 1971, с. 251-252; Саркисян, 1969, с. 176].

126 [Саркисян, 1969, с. 214; ИАН, 1984, с. 257-263; Дашков, 2008, с. 148 и слл; Фаррох, 2009, с. 266-267; Дьяконов, 1961, с. 314-315].

127 [Меринг, 1941]. Недавно вышла новая работа Дж. Вэрри. См. [Вэрри, 2004]. См. также [Нефедкин, 2003, с. 134-148]. 
В течение последнего десятилетия армянская историография сделала большой шаг в вопросе изучения древнеармянского военного искусства ${ }^{128}$. Однако все исследования в этой области носят историко-археологический харатер, и пока труд С.В. Саркисяна остается единственной сугубо военно-теоретической работой в армянской историографии.

\section{Список литературы}

1. Адонц Н.Г. 1971. Армения в эпоху Юстиниана. Изд. второе. Ереван, ЕГУ, 526.

2. Айвазян А.М. 2007. Краеугольные камни армянской идентичности. Армия, язык, государство. Ереван, Лусакн, 228 (на арм. яз.).

3. Айвазян А.М. 2000. Кодекс чести армянского воинства IV-V вв. Ереван, Артагерс, 302 (на арм. яз.).

4. Акопян А. 2013а. Армянская армия и боевые искусства в эпоху Ервандуни. Ереван, Принтинфо, 412 (серия «Армянские войны и боевые искусства») (на арм. яз.).

5. Акопян А. 2013b. Армянские войны и боевые искусства времен правления Тиграна Великого. Ереван, Принтинфо, 362 (серия «Армянские войны и боевые искусства») (на арм. яз.).

6. Арутюнян А.Ж. 2010. О местонахождении «Castellum Volandum» согласно Корнелию Тациту (историко-лингвистическое и географическое исследование). Вестник СПбУ. Серия 2. История. 2. июнь. 154-159.

7. Арутюнян А.Ж. 2012а. Царство Оронтидов согласно «Описанию земли» Гекатея Милетского. Иран-Наме: научный востоковедческий журнал. 3. Алматы: 150-174.

8. Арутюнян А.Ж. 2012b. Возникновение института губерний на территории древнеармянского государства (согласно античным историкам). МАИАСП. 4: 47-54.

9. Арутюнян А.Ж. 2014а. К разгадке тайны имени Лукулла-Вайкуна. Вестник Удмуртского университета. Серия 5. История и филология. Ижевск: 81-86.

10. Арутюнян А.Ж. 2014b. Марды в военно-политической истории Аршакидской Армении. Военно-исторический журнал Parabellum. СПб., 2 (35). 74-81.

11. Арутюнян Б. 2013. Вооружение Аршакидского царства Великой Армении и боевые искусства. Ереван, Принтинфо, 365 (серия «Армянские войны и боевые искусства») (на арм. яз.).

Эксмо, 232.

12. Вэрри Дж. 2003. Войны античности от греко-персидских войн до падения Рима. М.,

13. Геворгян А.М. 2009-2011. Войско Тиграна Великого (95-55 гг. до н. э.). Т. І. Ереван, 2009. T. II. Ереван, 2010. Т. III. Ереван, Айастан, 2011 (на арм. яз.).

14. Дашков С.Б. 2008. Цари царей Сасаниды. Иран III-VII вв. в легендах, исторических хрониках и современных исследованиях. М., СМИ-АЗИЯ, 352.

15. Демоян А. 2009а. Вооружение бронзового века и боевые искусства Армянского нагорья. Ереван, Принтинфо, 288 (серия «Армянские войны и боевые искусства») (на арм. яз.).

16. Демоян А. 2009b. Войны и боевые искусства Ванского царства. Ереван, Принтинфо, 312 (серия «Армянские войны и боевые искусства») (на арм. яз.).

17. Дьяконов М.М. 1961. Очерк истории древнего Ирана. М., Изд. Восточной лит., 444.

18. История армянского народа. 1971. Т. І. Армения в эпоху первобытнообщинного и рабовладельческого строя. Под ред. С.Т. Еремяна. Ереван, АН Арм. ССР, 756 (на арм. яз.).

19. История армянского народа. 1984. Армения в период раннего феодализма. Т. II. Под ред. С.Т. Еремяна. Ереван, АН Арм. ССР, 885 (на арм. яз.).

20. Кащеев В.И. 1993. Эллинистический мир и Рим. Война, мир и дипломатия в 220-146 гг. до н. э. М., Греко-латинский кабинет Ю.А. Шичалина, 380.

21. Лечебник лошадей и вообще вьючных животных (XIII в.). 1980. од ред. Б.Л. Чугасзяна. Ереван, Изд. АН Арм. ССР, 126 (на среднеарм. яз.).

22. Линч Х.Ф.Б. 1910. Армения: Путевые очерки и этюды. Т. І. Русские провинции. Т. II. Турецкие провинции. Тифлис, Изд Торгового дома «И.Е. Питоев и К».

23. Манандян Я.А. 1978. Труды. Т. ІІ. Ереван, АН Арм. ССР, 622 (на арм. яз.).

128 [Демоян, 2009a; Демоян, 2009b; Акопян, 2013a; Акопян, 2013b; Арутюнян, 2013; Геворгян, 2009-2011; Айвазян, 2007; Айвазян, 2000]. 
24. Меринг Ф. 1941. Очерки по истории войн и военного искусства. Предисл. Е. Разина. 4-е изд. М., Воениздат, 337.

25. Нефедкин А.К. 2003. Изучение античного военного искусства в России: историографический обзор. Studia historica. III: 134-148.

26. Разин Е.А. 1999. История военного искусства. В 3-х т. Т. 1. История военного искусства XXXI в. до н. э. - VI в. н. э. СПб., Полигон, 560. арм. яз.).

27. Саркисян С.В. 1969. Из истории армянского военного искусства. Ереван, Луйс, 420 (на

28. Фаррох К. 2009. Персы. Армия великих царей. М., Эксмо.

29. Poirot P.P. 2003. Perceptions of Classical Armenia: Romano-Parthian Relations, 70 B. C. A. D. 220. Lafayette, Louisiana, 89.

\section{References}

1. Adonts N.G. 1971. Armeniya v epokhu Yustinian [Armenia in the era of Justinian]. Erevan. Izd. «EGU», 526. Izd. vtoroe (in Russian).

2. Ayvazyan A.M. 2000. Kodeks chesti armyanskogo voinstva IV-V vv. [Code of honor of the armenian army IV-V centuries]. Erevan, Artagers, 302 (in Arm.).

3. Ayvazyan A.M. 2007. Kraeugol'nye kamni armyanskoy identichnosti. Armiya, yazyk, gosudarstvo [The cornerstones of armenian identity. Army, language, state]. Erevan, Lusakn, 228 (in Arm.).

4. Dashkov S.B. 2008. Tsari tsarey Sasanidy. Iran III-VII vv. v legendakh, istoricheskikh khronikakh i sovremennikh issledovaniyakh [Kings of Kings of Sassanids. Iran III-VII centuries in legends, historical chronicles and modern research]. M., SMI-AZIYA, 352 (in Russian).

5. Demoyan H. 2009a. Vooruzhenie bronzovogo veka i boevye iskusstva Armyanskogo nagor'ya [Bronze age weapons and martial arts of the Armenian highlands]. Erevan, Printinfo, 288 (series «Armenian Wars and Martial Arts» (in Arm.).

6. Demoyan H. 2009b. Voyny i boevye iskusstva Vanskogo korolevstva [Wars and martial arts of the kingdom of Van]. Erevan, Printinfo, 312 (series «Armenian Wars and Martial Arts» (in Arm.).

7. D'yakonov M.M. 1961. Ocherk istorii drevnego Irana [An outline of the history of ancient Iran]. M., Izd. «Vost. lit.», 444 (in Russian).

8. Farrokh K. 2009. Persy. Armiya velikikh tsarey [Persians: The Army of the Great Kings). M., Izd. «Eksmo» (in Russian).

9. Gevorgyan A.M. 2009-2011. Voysko Tigrana Velikogo (95-55 gg. do n.e.) [The army of Tigran the Great (95-55 B. C.)]. T. I. Erevan, 2009. T. II. Erevan, 2010, T. III. Erevan, Hayastan, 2011 (in Arm.).

10. Hakopyan H. 2013a. Armyanskaya armiya i boevye iskusstva v epokhu Ervanduni [Armenian army and martial arts in the Yervanduni era]. Erevan, Printinfo, 412 (series «Armenian Wars and Martial Arts») (in Arm.).

11. Hakopyan H. 2013b. Armyanskie voyny i boevye iskusstva vremyon pravleniya Tigrana Velikogo [Armenian wars and martial arts during the reign of Tigran the Great]. Erevan, Printinfo, 362 (series «Armenian Wars and Martial Arts») (in Arm.).

12. Harutyunyan A.Zh. 2010. O mestonahozhdenii «Castellum Volandum» soglasno Korneliju Tacitu (istoriko-lingvisticheskoe i geograficheskoe issledovanie) [On the location of «Castellum Volandum» according to Cornelius Tacitus (historical-linguistic and geographical research)]. In: Vestnik $\mathrm{SPbU}$. Seriya 2. Istoriya. 2. iyun' [SPbU Bulletin. Series 2. History. 2. Јune]. Вестник СПбУ. Серия 2. История. 2. Июнь. 154-159 (in Russian).

13. Harutyunyan A.Zh. 2012a. Carstvo Orontidov soglasno «Opisaniju zemli» Gekateja Miletskogo [Kingdom of Orontids according to the «Description of the Land» by Hecateus of Miletus]. In: Iran-Name: nauchnyy vostokovedcheskiy zhurnal [Iran-Nam: scientific oriental studies journal]. Almaty. 3: 150-174 (in Russian).

14. Harutyunyan A.Zh. 2012b. Vozniknovenie instituta gubernij na territorii drevnearmjanskogo gosudarstva (soglasno antichnym istorikam) [The emergence of the institution of provinces on the territory of the ancient Armenian state (according to ancient historians)]. In: Materialy po arkheologii i istorii antichnogo i srednevekovogo Prichernomor'ia [Proceedings in Archaeology and History of Ancient and Medieval Black Sea Region]. IV. 47-54 (in Russian). 
15. Harutyunyan A.Zh. 2014a. K razgadke tajny imeni Lukulla-Vajkuna [To unraveling the mystery of the name Lucullus-Vaikin]. In: Vestnik Udmurtskogo universiteta. Seriya 5. Istoriya i filologiya [Bulletin of the Udmurt University. Series 5. History and Philology]. Izhevsk (in Russian).

16. Harutyunyan A.Zh. 2014b. Mardy v voenno-politicheskoj istorii Arshakidskoj Armenii [Mardas in the military-political history of Arshakid Armenia]. In: Voyenno-istoricheskiy zhurnal Parabellum [Military history magazine Parabellum]. SPb. 2 (35): 74-81 (in Russian).

17. Harutyunyan B. 2013. Vooruzhenie Arshakidskogo korolevstva Velikoy Armenii i boevye iskusstva [Armament of the Arshakid kingdom of Great Armenia and martial arts]. Erevan, Printinfo, 365 (series «Armenian Wars and Martial Arts») (in Arm.).

18. Istoriya armyanskogo naroda. 1971. T. I. Armeniya v epokhu pervobytnoobshchinnogo i rabovladel'cheskogo stroya [Armenia in the era of the primitive communal and slave system]. Pod red. S.T. Eremyana Erevan, AN Arm. SSR, 756 (in Arm.).

19. Istoriya armyanskogo naroda. 1984. T. II. Armeniya v period rannego feodalizma [Armenia during the period of early feudalism]. Pod red. S.T. Eremyana. Erevan, AN Arm. SSR, 885 (in Arm.).

20. Kashcheev V.I. 1993. Ellinisticheskiy mir i Rim. Voyna, mir i diplomatiya v 220-146 gg. do n. e. [The Hellenistic World and Rome. War, Peace and Diplomacy in 220-146 B. C.]. M., Grekolatinskiy cabinet Yu.A. Shichalina, 380 (in Russian).

21. Lechebnik loshadey i voobshche v'yuchnykh zhivotnykh (XIII v.). 1980 [Healer for horses and beasts of burden in general (XIII century)]. Pod red. B.L. Chugaszyana. Erevan, AN Arm. SSR, 126 (in Middle Arm.).

22. Linch Kh.F.B. 1910. Armeniya: Putevyye ocherki i etyudy [Armenia: Travel Sketches and Etudes]. T. I. Russkiye provintsii [Russian provinces]. T. II. Turetskiye provintsii [Turkish provinces]. Tiflis, Izd. Torgovogo doma «I.E. Pitoev i K» (in Russian).

23. Manandyan Ya.A. 1978. Trudy [Works]. T. II. Erevan, AN Arm. SSR, 622 (in Arm.).

24. Mering F. 1941. Ocherki po istorii voyn i voyennogo iskusstva [Essays on the history of wars and military art]. Predisl. E. Razina. 4-eizd. M., Voenizdat, 337 (in Russian).

25. Nefyodkin A.K. 2003. Izuchenie antichnogo voennogo iskusstva v Rossii: istoriograficheskij obzor [The Study of Ancient Military Art in Russia: A Historiographic Review]. In: Studia historica. III: 134-148 (in Russian).

26. Razin E.A. 1999. Istoriya voyennogo iskusstva [History of military art]. V 3-kh. т. T. 1 [History of military art of the XXXI century. B. C. - VI century A. D.]. SPb., Poligon, 560 (in Russian).

27. Sarkicyan S.V. 1969. Iz istorii armyanskogo voyennogo iskusstva [From the history of Armenian military art]. Erevan, Luys, 420 (in Arm.).

28. Verri J. 2003. Voyny antichnosti ot greko-persidskikh voyn do padeniya Rima [The wars of antiquity from the Greco-Persian wars to the fall of Rome]. M., Eksmo, 232.

29. Poirot P.P. 2003. Perceptions of Classical Armenia: Romano-Parthian Relations, 70 B. C. A. D. 220. Lafayette, Louisiana, 89.

Конфликт интересов: о потенциальном конфликте интересов не сообщалось.

Conflict of interest: no potential conflict of interest related to this article was reported.

\section{ИНФОРМАЦИЯ ОБ АВТОРЕ}

Арутюнян Акоп Жораевич, доктор исторических наук, профессор кафедры всемирной истории Ереванского государственного университета, г. Ереван, Армения

Казаров Саркис Суренович, доктор исторических наук, профессор кафедры археологии и истории древнего мира Южного федерального университета, г. Ростов-на-Дону, Россия

\section{INFORMATION ABOUT THE AUTHOR}

Hakob Zh. Harutyunyan, Doctor of Historical Sciences, Professor of the Department of World History, Yerevan State University, Yerevan, Armenia

Sarkis S. Kazarov, Doctor of Historical Sciences, Professor of the Department of Archeology and History of the Ancient World, Southern Federal University, Rostov-on-Don, Russia 